\title{
Maternal education is associated with vaccination status of infants less than 6 months in Eastern Uganda: a cohort study
}

Victoria Nankabirwa ${ }^{1,2^{*}}$, Thorkild Tylleskär ${ }^{2}$, James K Tumwine ${ }^{1}$, Halvor Sommerfelt ${ }^{2,3}$, Promise-ebf Study Group ${ }^{2}$

\begin{abstract}
Background: Despite provision of free childhood vaccinations, less than half of all Ugandan infants are fully vaccinated. This study compares women with some secondary schooling to those with only primary schooling with regard to their infants' vaccination status.
\end{abstract}

Methods: A community-based prospective cohort study conducted between January 2006 and May 2008 in which 696 pregnant women were followed up to 24 weeks post partum. Information was collected on the mothers' education and vaccination status of the infants.

Results: At 24 weeks, the following vaccinations had been received: bacille Calmette-Guérin (BCG): 92\%; polio-1: 91\%; Diphteria-Pertussis-Tetanus-Hepatitis B-Haemophilus Influenza b (DPT-HB-Hib) 3 and polio-3: 63\%. About 51\% of the infants were fully vaccinated (i.e., had received all the scheduled vaccinations: BCG, polio 0, polio 1, DPT-HBHib1, polio 2, DPT-HB-Hib 2, polio 3 and DPT-HB-Hib 3). Only 46\% of the infants whose mothers' had 5-7 years of primary education had been fully vaccinated compared to $65 \%$ of the infants whose mothers' had some secondary education. Infants whose mothers had some secondary education were less likely to miss the DPT-HB-Hib-2 vaccine (RR: $0.5,95 \%$ Cl: $0.3,0.8$ ), Polio-2 (RR: $0.4,95 \% \mathrm{Cl}: 0.3,0.7$ ), polio-3 (RR: $0.5,95 \% \mathrm{Cl}: 0.4,0.7$ ) and DPT-HB-Hib-3 (RR: $0.5,95 \% \mathrm{Cl}: 0.4,0.7)$. Other factors showing some association with a reduced risk of missed vaccinations were delivery at a health facility (RR $=0.8 ; 95 \% \mathrm{Cl}: 0.7,1.0)$ and use of a mosquito net (RR: $0.8 ; 95 \% \mathrm{Cl}: 0.7,1.0)$.

Conclusion: Infants whose mothers had a secondary education were at least $50 \%$ less likely to miss scheduled vaccinations compared to those whose mothers only had primary education. Strategies for childhood vaccinations should specifically target women with low formal education.

\section{Background}

Routine childhood vaccinations against tuberculosis, polio, diphtheria, pertussis, tetanus, measles, hepatitis B and haemophilus influenza $B$ have been shown to be effective in protecting children against these diseases in low and middle income countries (LMIC) [1-3]. These vaccinations are highly cost-effective with respect to life years saved $[4,5]$. Yet, each year, an estimated thirty-four million children do not get vaccinated [4]. In the early 1980's, UNICEF, headed by James P. Grant, spearheaded a child survival campaign that focused mostly on oral rehydration and vaccination, interventions that were

\footnotetext{
* Correspondence: nankabirwav@gmail.com

'Department of Paediatrics and Child Health, School of Medicine, College of Health Sciences, Makerere University, Kampala, Uganda Full list of author information is available at the end of the article
}

seen as measurable [6]. This was followed by a remarkable global increase in vaccination coverage of diphtheria, pertussis and tetanus, from $25 \%$ to $75 \%$ in ten years [6]. However, this global success was not shared by all and today, about 1.4 million children still die each year from vaccine-preventable illnesses [7].

In fact, thirty years later, only $36 \%$ of all one-year old Ugandan children are fully immunized [8] and vaccinepreventable diseases continue to be a major contributor to under-five mortality and morbidity $[9,10]$. This is despite the fact that the Ugandan Ministry of Health provides free childhood vaccinations and has conducted several national immunization days (NIDs) [11]. The Uganda national expanded programme on immunization (UNEPI) schedule is BCG and polio at birth; polio+ Diphteria-Pertussis-Tetanus-Hepatitis B-Haemophilus
C Biomed Central 
Influenza b (DPT-HB-Hib) at 6, 10 and 14 weeks and measles at 9 months $[12,13]$. In Uganda, vaccination coverage increased in the late $1980 \mathrm{~s}$ and the early 1990 $\mathrm{s}$ and then stagnated, and even declined in some areas [14]. Several hypotheses for this stagnation such as maternal education have been posited in Uganda and other countries with comparable coverage $[15,16]$. Mother's education may increase the likelihood of vaccination through increasing knowledge on vaccination. Studies have shown a positive correlation between mother's education and knowledge of vaccination as well as between knowledge of vaccination and acceptance of vaccination [15].

In fact, maternal education may lead to improvements in utilization of primary health care services such as vaccination programmes and other child survival programmes [15-21]. The $2^{\text {nd }}$ millennium development goal is dedicated to universal primary education [17]. The Ugandan government and several other governments in Sub Saharan Africa and South Asia have embarked on an ambitious project to achieve universal primary education by 2015, with some success [17]. In 2007, the Ugandan government launched the universal secondary education scheme. Still, less than $27 \%$ of Ugandan women in the reproductive age group have had some secondary school education[8]. This paper compares women with primary school education with those having some secondary school education with regard to the BCG, polio and DPT-HB-Hib vaccination status of their infants.

\section{Methods}

The study was undertaken during a cluster-randomized intervention trial focussed on improving breastfeeding by individual peer counselling (Clinical trials gov: NCT00397150) [18]. Data collection for this study started in January 2006 and ended in May 2008.

\section{Study site}

The study was conducted in Mbale district, in Eastern Uganda, $300 \mathrm{~km}$ North-East of Kampala the capital city. The study area is served by Mbale Hospital, which doubles as the district and regional referral hospital. Most of the people were subsistence farmers. With an estimated population of 720,000 [19], Mbale district comprised of 7 counties; the study was conducted in the two biggest counties, namely Bungokho County (rural) and Mbale Municipality (urban). Twenty four clusters were included in the study, 18 rural and 6 urban. Six clusters in Mbale municipality were selected from all its three municipal divisions. Most of the urban areas were large informal settlements. Eighteen clusters in Bungokho County were chosen from eight of its eleven subcounties. Clusters were included if they neighboured the main road out from Mbale Municipality or were on the $1^{\text {st }}$ or $2^{\text {nd }}$ branch off the main road, had a population of at least 1,000 inhabitants and represented a social and administrative unit.

\section{Study subjects}

Between January 2006 and May 2008, all pregnant women in the selected clusters, were approached by the study team. They were eligible if they resided and intended to stay in the study area, were seven or more months pregnant, intended to breastfeed their infants and consented to participate in the study. In the trial, only singleton children were followed up. Eight hundred and eighty six pregnant women in the study area were identified and all of them were approached.

Written informed consent was obtained from each study participant. Ethical approval was obtained from the Makerere University Research and Ethics Committee, the Uganda National Council for Science and Technology and from the Regional Committee for Medical and Research Ethics for West Norway (REK VEST, approval number 05/8197).

\section{Data collection}

At recruitment, a pre-tested structured questionnaire in the local language (Lumasaaba) was administered by trained data collectors, fluent in the local language. Information was collected on socio-demographic characteristics, antenatal care attendance, marital status and the main source of income. Data was also collected on the current pregnancy and use of bed nets. The pregnant women were followed up until 24 weeks postpartum. After delivery, the mother-infant pairs were visited four times for data collection, at 3, 6, 12 and 24 weeks postpartum. At each of these visits, information was collected on the vaccination status of the children, health seeking behaviour, and breastfeeding practices. The vaccination status of each child was ascertained through inspection of the child's vaccination card by the data collectors. All births, deaths and details of the delivery were recorded within four weeks of delivery.

\section{Definitions}

We categorized marital status into three categories: 'married', 'cohabiting' and other (single, widowed, divorced and separated). In Uganda, it is now common to find couples living together without being formally married and these were classified as 'co-habiting'. Place of delivery was categorised into two groups: 'home', and 'health facility'. Parity was defined as the number of previous live births excluding the study child. Education was grouped into five categories: 'none' '1-4 years', '5-7 years', '8-11 years' and '12 or more years' Primary education was defined as 5-7 years and secondary education as 8-11 years of schooling. 
We created a composite index of wealth (socio-economic status) using multiple correspondence analysis (MCA). Because the MCA technique allows combination and ranking of a large number of variables into smaller and fewer variables without prejudgment, it is considered a more accurate indicator of socioeconomic status (SES) than single items such as occupation or possession of particular items. Also, in comparison to principal component analysis (PCA), the MCA technique is more appropriate for discrete variables. This was important in this study because several relevant variables could only be categorical. Furthermore, unlike PCA, which clusters variables together, MCA clusters the categories within these variables together. We used MCA on possession of a TV, radio, mobile phone, chair, cupboard, refrigerator, type of toilet, type of house walls as well as presence of electricity and water in the home. Scores were obtained and categorized into the poorest $20 \%$, middle $40 \%$ and richest $40 \%$. Full vaccination at 6 months was defined as having received all the scheduled vaccinations (BCG, polio 0, polio 1, DPT-HB-Hib1, polio 2, DPT-HB-Hib 2, polio 3 and DPT-HB-Hib 3). No-vaccination was not getting any of the vaccines and partial vaccination was having received at least one but not all of these scheduled vaccines.

\section{Data analysis}

Data was directly entered into handheld computers in the field using EpiHandy software (http://www.openXdata.org, version 165.528-142 RC). We analyzed the data with Stata version 9 (StataCorp LP, TX, U.S.). Frequencies and proportions for maternal age, education, parity, wealth, religion, residence, and marital status were calculated. Continuous variables were categorized to avoid doubtful assumptions about linearity. The outcome variables were bacille Calmette-Guérin (BCG) vaccination, polio 0-3 vaccinations and DPT-HB+Hib1-3 vaccinations. The exposure variable was education level. Crude relative risks (RR) and 95\% confidence intervals were estimated for the independent variable. We used multivariable generalized linear model (GLM) regression analysis with a log link to estimate the adjusted RR of the exposure variable on the outcome variables. We controlled for place of delivery and household wealth index in the adjusted analysis. In a secondary analysis using multivariable regression, we estimated the effect of maternal education, use of bed nets, delivery at a health facility, household wealth index, mother's age, parity and residence on full (age-appropriate vaccination at 6 months) versus partial vaccination. In both the main and secondary analyses, only variables that were associated with vaccination status yielding a P-value < 0.25 and household wealth index were included in the initial multivariable model. The importance of each of the variables included in the initial multivariable model was assessed based on the Wald statistic and a comparison of each estimated coefficient with the coefficient from the model with only that variable. Variables that did not significantly contribute to the model based on these criteria were eliminated from the final model [20]. The variable household wealth index was included in the multivariable model because of its scientific relevance. Taking the design effect of the PROMISE-EBF clusters into account had no effect on the RR and a negligible effect on precision.

\section{Results}

Of the 886 women approached to participate in the study, 875 (98.8\%) accepted to participate. After delivery, 75 participants were not eligible to participate in the study for the following reasons: delivery of stillbirths (17), twin deliveries (17), maternal deaths (2), cleft lip and cleft palate (1), infant deaths up to 24 weeks of age (27) and other reasons (12). In addition, 104 participants were lost to follow up, mostly because of relocation out of the study area. In total, 179 participants were lost to follow up. Of these, $23 \%$ had some secondary education compared to $25 \%$ of those that remained in the cohort at the end of the study. In both groups, $44 \%$ of the mothers had primary education. Data was analysed for the remaining 696 participants.

A total of 696 mother-infant pairs were followed up until 24 weeks post-partum. The mean age of the mothers was 25 years, (range 14 to 44 years) and they had an average of 7 years of formal education (range 0 to 16 years). Mean parity was 3.5 (range 1 to 14 ). In this cohort, 570 households (82\%) were headed by males. Only 177 (25\%) of the women earned money for themselves. Most women (72\%) had attended at least one antenatal visit by 7 months of gestation. About one half of the women (55\%) had been informed about voluntary HIV counselling and testing services, 271 (39\%) had been counselled and 212 (31\%) had been tested for HIV. In this study, 350 (50\%) infants were girls. The 254 children $(37 \%)$ that were weighed at birth had an average birth weight of $3.4 \mathrm{~kg}$ (SD 0.6, range 2 to $6 \mathrm{~kg}$ ). At 24 weeks, 284 (41\%) of the children had received vitamin A. Bed net use by children was $46 \%(320 / 696)$. The distribution of the mothers according to marital status was as follows: 433(62\%) were married, 206 (30\%) were cohabiting and $57(8 \%)$ were single, widowed, divorced or separated.

\section{Vaccinations}

Out of 696 children, 50 (7\%) had not received any vaccination by six months. The remaining 646 children had received some or all vaccinations (Table 1). At 24 weeks, 284 infants $(41 \%)$ had received vitamin A 
Table 1 Percentage of infants vaccinated at 24 weeks of age in a cohort of 696 infants in Mbale, Eastern Uganda

\begin{tabular}{lll}
\hline Vaccine received & $\mathbf{N}=\mathbf{6 9 6}$ & Proportion vaccinated $(\mathbf{9 5 \%} \mathbf{C l})^{*}$ \\
\hline BCG & 643 & $92(90,94)$ \\
Polio 0 & 518 & $74(71,78)$ \\
Polio 1 & 630 & $91(88,93)$ \\
DPT-HB-Hib 1 & 627 & $90(88,92)$ \\
Polio 2 & 558 & $80(77,83)$ \\
DPT-HB-Hib 2 & 554 & $80(76,82)$ \\
Polio 3 & 437 & $63(59,66)$ \\
DPT-HB-Hib 3 & 435 & $63(59,66)$ \\
\hline
\end{tabular}

* $\mathrm{Cl}$ indicates confidence interval

supplementation. The vaccination coverage increased with increasing level of education (Figure 1).

\section{Partial versus full vaccination at 6 months}

At 24 weeks, 355 (51\%) of the infants had received all the scheduled vaccinations (BCG, Polio 0-3, and DPTHB-Hib 1-3). Out of the 176 infants whose mothers' had some secondary education, 115 (65\%) were fully vaccinated at 24 weeks while 140 (46\%) of those whose mothers' only had a primary education were fully vaccinated. The proportion of children with missed vaccinations decreased as maternal education increased. Other factors associated with a reduced risk of missing their vaccinations were delivery at a health facility $(R R=0.8$; $95 \% \mathrm{CI}: 0.7,1.0)$ and use of a mosquito net $(\mathrm{RR}=0.8$; $95 \% \mathrm{CI}: 0.7,1.0)$. There was no association between vaccination status and wealth index (Table 2)

\section{Maternal education and vaccinations}

Out of the 696 women, 176 (25\%) had some secondary education while 305 (44\%) had primary education. For all vaccinations (BCG, polio 0-3 and DPT-HB-Hib1-3) women with some secondary education achieved higher vaccination coverage for their infants than women with a primary education (Figure 2). Vaccination coverage dropped steadily from BCG (the first vaccination) to DPT-HB-Hib 3, more so for those with only primary education (Figure 3). At 24 weeks, 177 (58\%) of those with primary education had their infants vaccinated with DPT-HB-Hib 3 while 135 (77\%) of those with a secondary education had had their children vaccinated with DPT-HB-Hib 3.

Infants whose mothers had a secondary education were less likely to miss polio-0, polio-2, DPT-HB-Hib 2, polio-3, and DPT-HB-Hib 3 vaccines compared to infants whose mothers had received only primary education (Table 3 ). After adjusting for potential confounders, infants of mothers having some secondary schooling were protected from missing the polio- 2 vaccine compared to those whose mothers only had been to primary school (RR: 0.4, CI: 0.3-0.7). In addition infants whose mothers had received some secondary education were $50 \%$ less likely to miss DPT-HB-Hib 2 (RR: 0.5, CI: 0.3-0.8), Polio-3 (RR: 0.5, CI: 0.4-0.7), and DPT-HB-Hib 3(RR: 0.5, CI: 0.4-0.7).

\section{Discussion}

There were substantial differences in vaccination coverage between women that had a primary education and

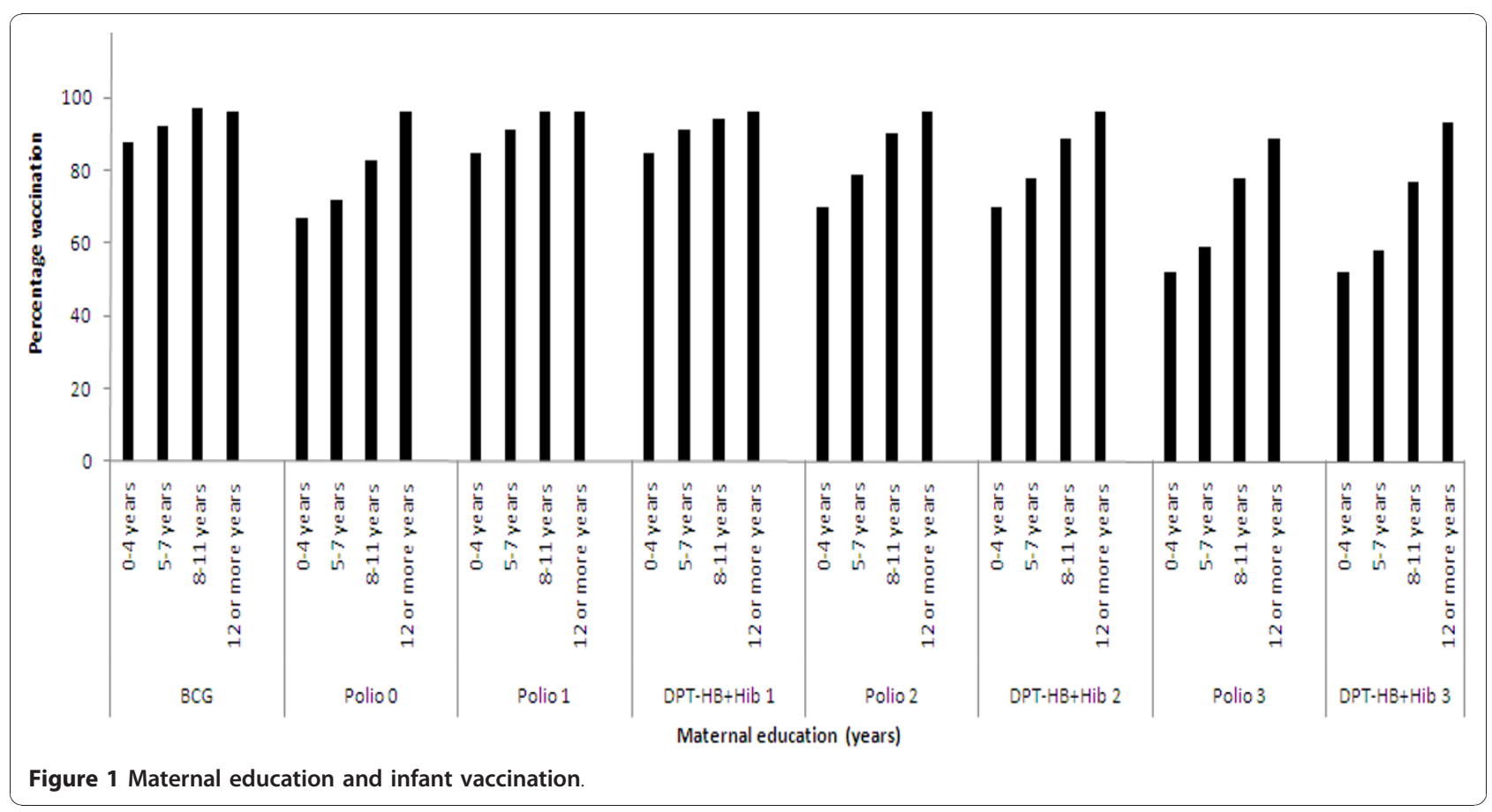


Table 2 Risk factors for partial vaccination at 24 weeks in a cohort of 696 children in Mbale, Eastern Uganda*¥

\begin{tabular}{|c|c|c|c|c|}
\hline Characteristic & $\begin{array}{l}\text { Number } \\
(\%)\end{array}$ & $\begin{array}{l}\text { Unadjusted RR } \\
(95 \% \mathrm{Cl}) \dagger\end{array}$ & $\begin{array}{l}\text { Adjusted RR** } \\
(95 \% \mathrm{Cl})\end{array}$ & $\begin{array}{l}\text { Adjusted RRs**** } \\
(95 \% \mathrm{Cl})\end{array}$ \\
\hline \multicolumn{5}{|l|}{ Mothers education } \\
\hline None & $64(9 \%)$ & 1 & 1 & 1 \\
\hline $1-4$ years & $124(18 \%)$ & $1.0(0.8,1.2)$ & $0.9(0.7,1.2)$ & $1.0(0.7,1.2)$ \\
\hline 5-7 years & 305 (44\%) & $0.9(0.7,1.1)$ & $0.9(0.7,1.1)$ & $0.9(0.7,1.1)$ \\
\hline $8-11$ years & $176(25 \%)$ & $0.6(0.4,0.8)$ & $0.6(0.4,0.8)$ & $0.6(0.5,0.8)$ \\
\hline 12 or more years & $27(4 \%)$ & $0.2(0.1,0.5)$ & $0.2(0.1,0.6)$ & $0.2(0.1,0.6)$ \\
\hline \multicolumn{5}{|l|}{ Place of delivery } \\
\hline Home & $302(43 \%)$ & 1 & 1 & 1 \\
\hline Health facility & $394(57 \%)$ & $0.8(0.7,0.9)$ & $0.8(0.7,1.0)$ & $0.8(0.7,1.0)$ \\
\hline \multicolumn{5}{|l|}{ Use of Mosquito net } \\
\hline No & $376(54 \%)$ & 1 & 1 & 1 \\
\hline Yes & $320(46 \%)$ & $0.7(0.6,0.8)$ & $0.8(0.7,0.9)$ & $0.8(0.7,1.0)$ \\
\hline \multicolumn{5}{|l|}{ Wealth quintiles } \\
\hline Poorest 20\% & $146(21 \%)$ & 1 & 1 & \\
\hline Middle 40\% & $280(40 \%)$ & $1.0(0.8,1.2)$ & $1.0(0.8,1.2)$ & \\
\hline Richest 40\% & $270(30 \%)$ & $0.9(0.7,1.1)$ & $1.1(1.0,1.4)$ & \\
\hline \multicolumn{5}{|l|}{ Mother's age } \\
\hline$\leq 19$ & $153(22 \%)$ & 1 & & \\
\hline $20-24$ & $227(33 \%)$ & $0.9(0.7-1.1)$ & & \\
\hline $25-29$ & 165 (24\%) & $0.9(0.8,1.2)$ & & \\
\hline$\geq 30$ & $152(22 \%)$ & $1.1(0.9,1.3)$ & & \\
\hline \multicolumn{5}{|l|}{ Residence } \\
\hline Rural & $554(80 \%)$ & 1 & & \\
\hline Urban & $142(20 \%)$ & $0.9(0.7,1.0)$ & & \\
\hline \multicolumn{5}{|l|}{ Parity } \\
\hline 0 & $160(23 \%)$ & 1 & & \\
\hline $1-2$ & $210(30 \%)$ & $1.0(0.8,1.3)$ & & \\
\hline $3-4$ & $163(23 \%)$ & $1.3(1.1,1.7)$ & & \\
\hline 5 or more & $163(23 \%)$ & $1.3(1.1,1.7)$ & & \\
\hline
\end{tabular}

$+\mathrm{Cl}$ indicates confidence interval

\# Partial vaccination was defined as defined as having received at least one but not all the scheduled vaccinations

* $\mathrm{RR}<1$ indicate reduced risk of missed vaccination

** Model with maternal education, place of delivery, use of mosquito nets and wealth quintiles

*** Model with maternal education, place of delivery and use of mosquito nets

those with some secondary school education. At 24 weeks, only $46 \%$ of the mothers with only a primary school education had their children fully vaccinated compared to $65 \%$ of those with secondary school education. Infants whose mothers' had some secondary education were on an average 50\% less likely to miss Polio-2, DPT-HB-Hib 2, Polio-3 and DPT-HB-Hib 3 vaccinations. The findings of this cohort study reveal a strong relationship between mothers' education level and the vaccination status of their infants. We also show that this relationship grows stronger as the vaccinations proceed from BCG to DPT-HB-Hib 3. The vaccination coverage is highest with $B C G$, the first vaccination, and declines steadily with subsequent vaccinations and child age. A similar drop is seen in national estimates [8,21]. In this study, the decline is greatest for those with the least education (0-4 years of education).

Overall, $63 \%$ of the children in this study received DPT-HB-Hib 3. This is consistent with the national estimates (63\%-68\%) in 2007 [22]. However, a coverage of 


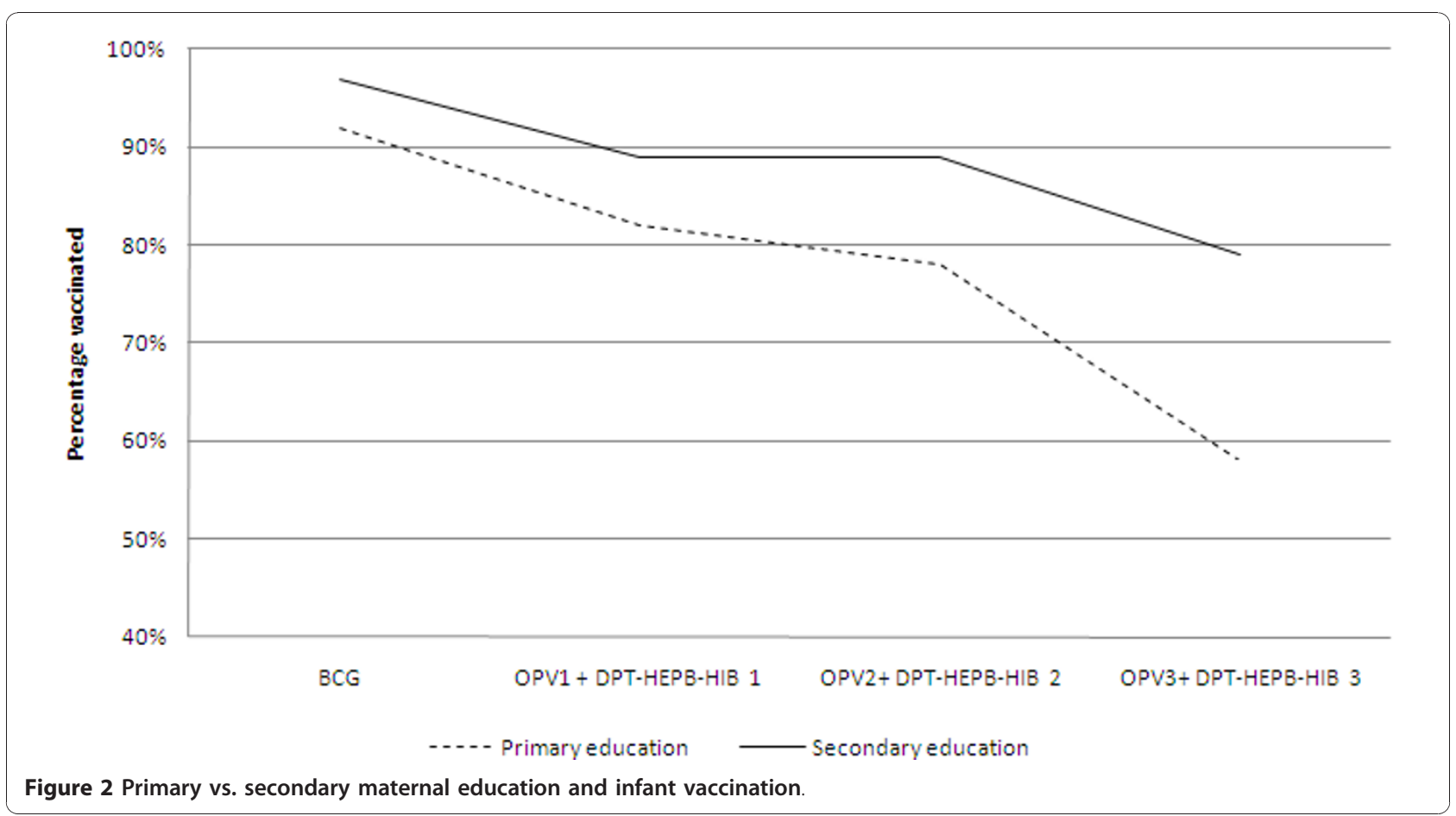

$58 \%$ among infants whose mothers only had a primary education is less than the national estimate and also way below both the regional estimate for Sub-Saharan Africa of $73 \%$ and the global estimate of $80 \%$ [22]. Several studies have shown that maternal education is associated with better utilization of health care services [15,23-26]. Findings from this study are consistent with this. However, we also found that mothers with some secondary schooling made better use of the vaccination programme. Studies elsewhere have also found that levels

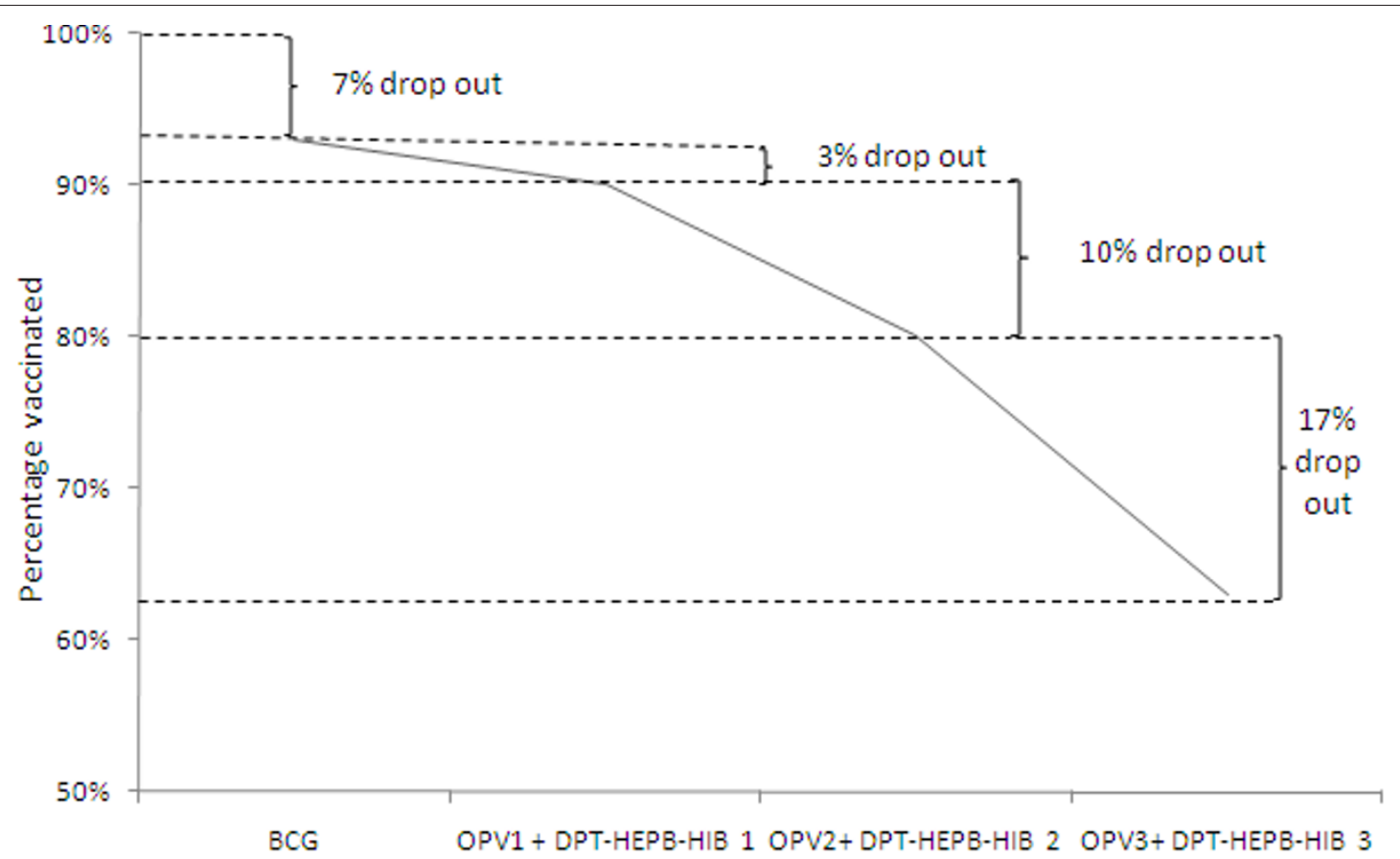

Figure 3 Percentage drop-out from the immunization schedule. 
Table 3 Unadjusted and adjusted risks ratios comparing the vaccination status of 6 month old infants of mothers with only a primary education to infants of mothers with some secondary

\begin{tabular}{|c|c|c|c|c|c|}
\hline Modelt & Vaccination & $\begin{array}{l}\text { Primary education } \\
(n=304)\end{array}$ & $\begin{array}{l}\text { Secondary education } \\
(n=176)\end{array}$ & $\begin{array}{l}\text { Unadjusted RR } \\
(95 \% \mathrm{Cl})^{*}\end{array}$ & $\begin{array}{l}\text { Adjusted RR } \\
(95 \% \mathrm{Cl})^{*}\end{array}$ \\
\hline \multirow[t]{3}{*}{1} & $B C G$ & & & & \\
\hline & No & $23(8 \%)$ & $6(3 \%)$ & 1 & 1 \\
\hline & Yes & 281 (92\%) & 170 (97\%) & $0.5(0.2,1.1)$ & $0.4(0.2,1.0)$ \\
\hline \multirow[t]{3}{*}{2} & Polio 0 & & & & \\
\hline & No & $84(28 \%)$ & $30(17 \%)$ & 1 & 1 \\
\hline & Yes & $220(72 \%)$ & $146(83 \%)$ & $0.6(0.4,0.9)$ & $0.7(0.5,1.0)$ \\
\hline \multirow[t]{3}{*}{3} & Polio1 & & & & \\
\hline & No & $28(9 \%)$ & $8(4 \%)$ & 1 & 1 \\
\hline & Yes & 276 (91\%) & 168 (96\%) & $0.5(0.2,1.0)$ & $0.4(0.2,0.9)$ \\
\hline \multirow[t]{3}{*}{4} & DPT-HB-Hib 1 & & & & \\
\hline & No & $28(9 \%)$ & $10(6 \%)$ & 1 & 1 \\
\hline & Yes & 276 (91\%) & 166 (94\%) & $0.6(0.3,1.2)$ & $0.5(0.3,1.1)$ \\
\hline \multirow[t]{3}{*}{5} & Polio 2 & & & & \\
\hline & No & $65(21 \%)$ & $18(10 \%)$ & 1 & 1 \\
\hline & Yes & 239 (79\%) & 158 (90\%) & $0.5(0.3,0.8)$ & $0.4(0.3,0.7)$ \\
\hline \multirow[t]{3}{*}{6} & DPT-HB-Hib 2 & & & & \\
\hline & No & $66(22 \%)$ & $20(11 \%)$ & 1 & 1 \\
\hline & Yes & 238 (78\%) & 156 (89\%) & $0.5(0.3,0.8)$ & $0.5(0.3,0.8)$ \\
\hline \multirow[t]{3}{*}{7} & Polio 3 & & & & \\
\hline & No & $126(41 \%)$ & 39 (22\%) & 1 & 1 \\
\hline & Yes & 178 (59\%) & 137 (78\%) & $0.5(0.4,0.7)$ & $0.5(0.4,0.7)$ \\
\hline \multirow[t]{3}{*}{8} & DPT-HB-Hib 3 & & & & \\
\hline & No & $127(42 \%)$ & $41(23 \%)$ & 1 & 1 \\
\hline & Yes & 177 (58\%) & 135 (77\%) & $0.6(0.4,0.8)$ & $0.5(0.4,0.7)$ \\
\hline
\end{tabular}

† Each model is adjusted for wealth index and place of delivery

${ }^{*} \mathrm{Cl}$ indicates confidence interval

of knowledge and use of vaccination services are greater for women with at least some secondary schooling [26-29]. The second millennium development goal is dedicated to ensuring that all children everywhere attain a full course of primary education. Indeed targeted investments and political will have resulted in widespread progress, with many regions reaching 90\%, and Sub-Saharan Africa reaching 70\% school enrolment [17]. However, for optimal vaccination coverage, secondary education may further contribute to enhancing vaccination coverage. Presently, 54\% of all children in developing countries attend secondary school while in Sub-Saharan Africa, only a quarter of the children of secondary school age attend secondary school [17]. In order to improve utilization of primary health care services, especially vaccination programmes, our findings indicate that there may be a need to target resources to women with low formal education.

In addition to secondary education of the mother, other factors that were associated with reduced risks of missing scheduled vaccinations were delivery at a hospital or health centre and use of mosquito bed nets. A study in Papua New Guinea reported that $70 \%$ of study participants learnt about when to take their children for vaccination from the local maternal and child health $(\mathrm{MCH})$ staff [23]. This could be an important reason for why women who delivered at health facilities were more likely to have their children fully vaccinated.

Wealth was not associated with childhood vaccination in this cohort. Though this finding is similar to other findings in the Philippines [28] and Guinea [30] it contrasts findings in Ghana [31]. Moreover, a systematic 
review of recent demographic and health survey data from 54 countries found that in comparison to other health care services, vaccination services had the smallest coverage gap between the poorest and richest quintiles of the population [32]. The highly precise estimate of family wealth not being associated with the risk of missing childhood vaccination represents a strong support for The Ugandan Government's policy of providing childhood vaccination services at no direct cost.

In this paper, we did not have data enabling us to adjust for distance to the health centres. Although this is a weakness of the study, it is unlikely to have caused substantial confounding of the results as all the study areas were within 30 minutes by car to a local health centre. Most of these centres vaccinate children on scheduled days. The strength of this study lies in the fact that it was a community-based prospective cohort study with a high follow-up. Only $19 \%$ of the motherinfant pairs eligible after delivery were lost to follow-up. There was no significant difference between those lost to follow-up and those that remained in the study with regard to education level. Because it is unlikely that the loss to follow up was unequal by vaccination status, we do not expect it to have substantially biased the estimated risk ratios. Generalizability in this study is limited by the fact that clusters included in this study were close to main roads. We believe these findings can be applicable to regions with similar socio-demographic characteristics because nearly all children in the study villages were recruited into the study. This study was a secondary analysis of data from a cluster randomized trial to improve breastfeeding, and as such, two mothers were not included in the main study because they did not intend to breastfeed. However, it is unlikely that these exclusions would affect our findings. Also, the endpoint of this analysis is 24 weeks of age because that was the endpoint for the breastfeeding trial. To the best of our knowledge, this is one of a few prospective community-based cohort studies on this topic done in a low-income country.

\section{Conclusion}

Women with secondary education were at least $50 \%$ less likely to miss their infants' scheduled vaccinations compared to women with only a primary school education. Resources for routine childhood vaccinations should specifically be targeted at women with low formal education.

\section{Acknowledgements}

The authors express their gratitude to the mothers who participated in the study and all those that took part in the data collection. Jolly Nankunda, Caleb Bwengye, Namboozo Rachael, Nandudu Evelyne, Mukwana Moses, Mugooda Herbert, Nambuya Doreen, Wetaaya Fred and Mariam Kituyi are recognized and thanked for their tremendous contribution during data collection.

Financial support

The study was part of the EU-funded project PROMISE-EBF (contract no INCO-CT 2004-003660, web http://www.promiseresearch.net). It was also financially supported by the University of Bergen and NUFU

List of Members for the PROMISE-EBF Study Group:

Steering Committee:

Thorkild Tylleskär, Philippe Van de Perre, Eva-Charlotte Ekström, Nicolas Meda, James K.Tumwine, Chipepo Kankasa, Debra Jackson.

Participating countries and investigators:

Norway: Thorkild Tylleskär, Ingunn MS Engebretsen, Lars Thore Fadnes, Eli

Fjeld, Knut Fylkesnes, Jørn Klungsøyr, Anne Nordrehaug-Åstrøm, Øystein

Evjen Olsen, Bjarne Robberstad, Halvor Sommerfelt

France: Philippe Van de Perre

Sweden: Eva-Charlotte Ekström

Burkina Faso: Nicolas Meda, Hama Diallo, Thomas Ouedrago, Jeremi Rouamba, Bernadette Traoré Germain Traoré, Emmanuel Zabsonré Uganda: James K. Tumwine, Caleb Bwengye, Charles Karamagi, Victoria Nankabirwa, Jolly Nankunda, Grace Ndeezi, Margaret Wandera

Zambia: Chipepo Kankasa, Mary Katepa-Bwalya, Chafye Siuluta, Seter Siziya South Africa: Debra Jackson, Mickey Chopra, Mark Colvin, Tanya Doherty, Ameena E ooga, Lyness Matizirofa, Lungiswa Nkonki, David Sanders, Wanga Zembe.

(Country PI first, others in alphabetical order of surname)

\section{Author details}

${ }^{1}$ Department of Paediatrics and Child Health, School of Medicine, College of Health Sciences, Makerere University, Kampala, Uganda. ${ }^{2}$ Centre for International Health, University of Bergen, Bergen, Norway. ${ }^{3}$ Division of Infectious Disease Control, Norwegian Institute of Public Health, Oslo, Norway.

\section{Authors' contributions}

All authors participated in the design and plan of the study. Field work was conducted by VN supported by $\Pi$ T and JKT. Analysis and write-up was done by VN, HS, JKT and TT. All authors read and approved the final manuscript.

\section{Competing interests}

The authors declare that they have no competing interests.

Received: 21 June 2010 Accepted: 15 December 2010

Published: 15 December 2010

\section{References}

1. Danielsson N, Fakakovikaetau T, Szegedi E: Improved immunization practices reduce childhood hepatitis B infection in Tonga. Vaccine 2009, 27(33):4462-4467.

2. Lee EH, Lewis RF, Makumbi I, Kekitiinwa A, Ediamu TD, Bazibu M, Braka F, Flannery B, Zuber PL, Feikin DR: Haemophilus influenzae type b conjugate vaccine is highly effective in the Ugandan routine immunization program: a case-control study. Trop Med Int Health 2008, 13(4):495-502.

3. Batson A: Sustainable introduction of affordable new vaccines: the targeting strategy. Vaccine 1998, 16(Suppl):S93-98.

4. Martin JF, Marshall J: New tendencies and strategies in international immunisation: GAVI and The Vaccine Fund. Vaccine 2003, 21(7-8):587-592.

5. Rwashana AS, Williams DW, Neema S: System dynamics approach to immunization healthcare issues in developing countries: a case study of Uganda. Health Informatics J 2009, 15(2):95-107.

6. Lawn JE, Rohde J, Rifkin S, Were M, Paul VK, Chopra M: Alma-Ata 30 years on: revolutionary, relevant, and time to revitalise. Lancet 2008, 372(9642):917-927

7. Vaccine Preventable diseases. [http://www.who.int/ immunization_monitoring/diseases/en/]

8. Uganda Demographic and Health survey 2006. Calverton, Maryland, USA Uganda Bureau of Statistics (UBOS) and Macro Internatioanl Inc and Macro Internatioal Inc 2007.

9. Boschi-Pinto C, Velebit L, Shibuya K: Estimating child mortality due to diarrhoea in developing countries. Bull World Health Organ 2008, 86(9):710-717. 
10. Rudan I, Boschi-Pinto C, Biloglav Z, Mulholland K, Campbell H: Epidemiology and etiology of childhood pneumonia. Bull World Health Organ 2008, 86(5):408-416.

11. Nuwaha F, Mulindwa G, Kabwongyera E, Barenzi J: Causes of low attendance at national immunization days for polio eradication in Bushenyi district, Uganda. Trop Med Int Health 2000, 5(5):364-369.

12. Communication strategy for revitalisation of routine childhood immunisation in Uganda. 2001-2005. [http://www.google.com/search?q= $\% 22$ Communication+strategy+for+revitalisation+of+routine+childhood +immunisation+in+Uganda\%22\&hl=en\&num = $10 \& \mid r=\& f t=i \& c r=\&$ safe=images $].$

13. UNEPI standards. [http://www.basics.org/documents/pdf/UNEPI\% 20Standards.pdf].

14. WHO/UNICEF: Uganda. Review of National Immunization Coverage 198020082009.

15. Bhuiya A, Bhuiya I, Chowdhury M: Factors affecting acceptance of immunization among children in rural Bangladesh. Health Policy Plan 1995, 10(3):304-312.

16. Victora CG, Huttly SR, Barros FC, Lombardi C, Vaughan JP: Maternal education in relation to early and late child health outcomes: findings from a Brazilian cohort study. Soc Sci Med 1992, 34(8):899-905.

17. The Millennium Development Goals Report 2008. [http://www.un.org/ millenniumgoals/pdf/The\%20Millennium\%20Development\%20Goals\% 20Report\%202008.pdf].

18. Jackson M, Tylleskar T, Chopra, Diallo H, Doherty T, Ekstrom C, Engebretsen I, Goga A, Kankasa C, Klunsoyr J, et al: Preliminary results from the multi-center cluster-randomized behaviour intervention trial PROMISE EBF: Exclusive breastfeeding promotion in Sub-Saharan Africa. American Public Health Association 137th annual meeting and expo Philadelphia, Pennsylvania; 2009.

19. UBOS: Uganda Population and Housing Census. Kampala: Bureau of Statistics 2002.

20. Hosmer W, Lemeshow S: Applied Logistic Regression. New York: John Wiley \& Sons, Inc; Second 2000.

21. Immunization profile-Uganda. [http://www.who.int/ immunization_monitoring/en/globalsummary/countryprofileresult.cfm]

22. Immunization sumary A statistical reference containing data through 2007. [http://www.childinfo.org/files/Immunization_Summary_2009.pdf].

23. Freeman PA, Thomason JA, Bukenya GB: Factors affecting the use of immunization among urban settlement dwellers in Papua New Guinea. PN G Med J 1992, 35(3):179-185.

24. Majumder AK, Islam SM: Socioeconomic and environmental determinants of child survival in Bangladesh. J Biosoc Sci 1993, 25(3):311-318.

25. Perry $H$, Weierbach $R$, Hossain I, Islam R: Childhood immunization coverage in zone 3 of Dhaka City: the challenge of reaching impoverished households in urban Bangladesh. Bull World Health Organ 1998, 76(6):565-573.

26. Racine $A D$, Joyce $T J$ : Maternal education, child immunizations, and public policy: evidence from the US National Immunization Survey. Soc Sci Med 2007, 65(8):1765-1772.

27. Streatfield K, Singarimbun M, Diamond I: Maternal education and child immunization. Demography 1990, 27(3):447-455.

28. Bondy JN, Thind A, Koval JJ, Speechley KN: Identifying the determinants of childhood immunization in the Philippines. Vaccine 2009, 27(1):169-175.

29. Odusanya OO, Alufohai EF, Meurice FP, Ahonkhai VI: Determinants of vaccination coverage in rural Nigeria. BMC Public Health 2008, 8:381.

30. Millimouno D, Diallo A, Fairhead J, Leach M: The social dynamics of infant immunisation in Africa: the case of the republic of Guinea. Forthcoming IDS Working Paper 2006.

31. Brugha $\mathrm{R}$, Kevany J: Immunization determinants in the eastern region of Ghana. Health Policy Plan 1995, 10(3):312-318.

32. Boerma JT, Bryce J, Kinfu Y, Axelson H, Victora CG: Mind the gap: equity and trends in coverage of maternal, newborn, and child health services in 54 Countdown countries. Lancet 2008, 371(9620):1259-1267.

\section{Pre-publication history}

The pre-publication history for this paper can be accessed here: http://www.biomedcentral.com/1471-2431/10/92/prepub

doi:10.1186/1471-2431-10-92

Cite this article as: Nankabirwa et al: Maternal education is associated with vaccination status of infants less than 6 months in Eastern Uganda: a cohort study. BMC Pediatrics 2010 10:92.

\section{Submit your next manuscript to BioMed Central and take full advantage of:}

- Convenient online submission

- Thorough peer review

- No space constraints or color figure charges

- Immediate publication on acceptance

- Inclusion in PubMed, CAS, Scopus and Google Scholar

- Research which is freely available for redistribution

Submit your manuscript at www.biomedcentral.com/submit
C) Biomed Central 